\title{
Author Correction: Circular RNA CircFndc3b modulates cardiac repair after myocardial infarction via FUS/VEGF-A axis
}

Venkata Naga Srikanth Garikipati, Suresh Kumar Verma, Zhongjian Cheng (1), Dongming Liang, May M. Truongcao, Maria Cimini, Yujia Yue, Grace Huang, Chunlin Wang, Cindy Benedict, Yan Tang, Vandana Mallaredy, Jessica Ibetti, Laurel Grisanti, Sarah M. Schumacher, Erhe Gao, Sudarsan Rajan, Jeremy E. Wilusz (D, David Goukassian, Steven R. Houser, Walter J. Koch \& Raj Kishore

Correction to: Nature Communications https:/doi.org/10.1038/s41467-019-11777-7, published online 20 September 2019.

The original version of this Article contained errors in the references 45, 46, 47, 48,49 which incorrectly cited:

45. Ji, L. \& Roth, J. A. Tumor suppressor FUS1 signaling pathway. J. Thorac. Oncol.: Off. Publ. Int. Assoc. Study Lung Cancer 3, 327-330 (2008).

46. Deng, W. G. et al. Synergistic tumor suppression by coexpression of FUS1 and p53 is associated with down-regulation of murine double minute- 2 and activation of the apoptotic protease-activating factor 1-dependent apoptotic pathway in human non-small cell lung cancer cells. Cancer Res. 67, 709-717 (2007).

47. Hesson, L. B., Cooper, W. N. \& Latif, F. Evaluation of the 3p21.3 tumour-suppressor gene cluster. Oncogene 26, 7283-7301 (2007).

48. Lin, J. et al. Oncogenic activation of c-Abl in non-small cell lung cancer cells lacking FUS1 expression: inhibition of c-Abl by the tumor suppressor gene product Fus1. Oncogene 26, 6989-6996 (2007).

49. Rimkus, T., Sirkisoon, S., Harrison, A. \& Lo, H. W. Tumor suppressor candidate 2 (TUSC2, FUS-1) and human cancers. Discov. Med. 23, 325-330 (2017).

The correct references are:

45. Tan, A.Y., Riley, T.R., Coady, T., Bussemaker, H.J. \& Manley, J.L. TLS/FUS (translocated in liposarcoma/fused in sarcoma) regulates target gene transcription via single-stranded DNA response elements. Proc. Natl Acad. Sci. USA 109, 6030-6035 (2012).

46. Ward, C. L. et al. A loss of FUS/TLS function leads to impaired cellular proliferation. Cell Death Dis. 5, e1572 (2014).

47. Crivello, M. et al. Vascular regression precedes motor neuron loss in the FUS (1-359) ALS mouse model. Dis. Model Mech. 12, (2019).

48. Suzuki, H. \& Matsuoka, M. Overexpression of nuclear FUS induces neuronal cell death. Neuroscience 287, 113-124 (2015).

49. Brooke, G.N. et al. FUS/TLS is a novel mediator of androgen-dependent cell-cycle progression and prostate cancer growth. Cancer Res. 71, 914-924 (2011).

Consequently, text referring to the incorrect references needed to be corrected. In the sentence "In corroboration with previous reports, we find that circFndc3b interacts with FUS, an RNA binding protein that acts as a tumor suppressor gene in many human cancers45", the statement "that acts as a tumor suppressor gene in many human cancers 45 " was incorrect and has been removed. 
In the sentence "Furthermore, recent studies demonstrated exogenous FUS gene delivery significantly inhibits tumor growth49 by activating APAF-1 induced apoptosis and inhibiting angiogenesis by reducing VEGF-A expression46", the statement "by activating APAF-1 induced apoptosis and inhibiting angiogenesis by reducing VEGF-A expression46" was incorrect and has been removed.

This has been corrected in the PDF and HTML versions of the Article.

Published online: 01 May 2020

(c) Open Access This article is licensed under a Creative Commons Attribution 4.0 International License, which permits use, sharing, adaptation, distribution and CyY reproduction in any medium or format, as long as you give appropriate credit to the original author(s) and the source, provide a link to the Creative Commons license, and indicate if changes were made. The images or other third party material in this article are included in the article's Creative Commons license, unless indicated otherwise in a credit line to the material. If material is not included in the article's Creative Commons license and your intended use is not permitted by statutory regulation or exceeds the permitted use, you will need to obtain permission directly from the copyright holder. To view a copy of this license, visit http://creativecommons.org/licenses/by/4.0/.

(C) The Author(s) 2020 